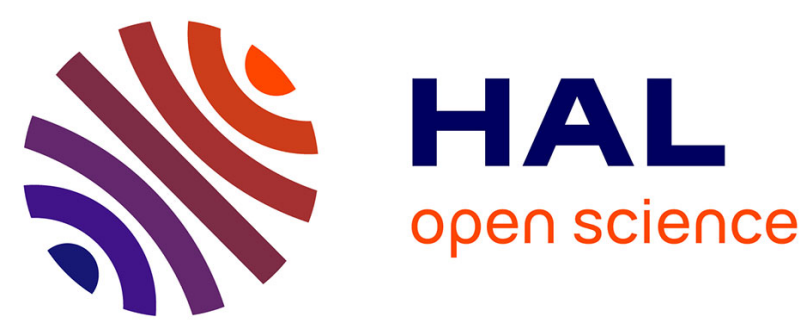

\title{
Modelling Interactions Between Health Institutions in the Context of Patient Care Pathway
}

\author{
Sabri Hamana, Vincent Augusto, Xiaolan Xie
}

\section{To cite this version:}

Sabri Hamana, Vincent Augusto, Xiaolan Xie. Modelling Interactions Between Health Institutions in the Context of Patient Care Pathway. 16th Working Conference on Virtual Enterprises (PROVE), Oct 2015, Albi, France. pp.448-455, 10.1007/978-3-319-24141-8_41 . hal-01278425

\section{HAL Id: hal-01278425 \\ https://hal.science/hal-01278425}

Submitted on 24 Feb 2016

HAL is a multi-disciplinary open access archive for the deposit and dissemination of scientific research documents, whether they are published or not. The documents may come from teaching and research institutions in France or abroad, or from public or private research centers.
L'archive ouverte pluridisciplinaire HAL, est destinée au dépôt et à la diffusion de documents scientifiques de niveau recherche, publiés ou non, émanant des établissements d'enseignement et de recherche français ou étrangers, des laboratoires publics ou privés. 


\title{
Modelling Interactions between Health Institutions in the Context of Patient Care Pathway
}

\author{
Sabri Hamana ${ }^{1}$, Vincent Augusto ${ }^{1}$ and Xiaolan $\mathrm{Xie}^{1}$, \\ ${ }^{1}$ UMR CNRS 6158 LIMOS, Centre for Biomedical and Healthcare Engineering, \\ MINES Saint-Etienne, 158 cours Fauriel 42023 Saint-Etienne cedex 2 France; \\ \{sabri.hamana, augusto, xie\}@ mines-stetienne.fr
}

\begin{abstract}
Health systems around the world have been continuously subject to many questions about their performance. In order to improve the functioning of such systems, Health Information Systems (HIS) and Technologies (HIT) are deployed to support patient care pathways and ensure information exchange between health structures, actors of patient care. The aim of this paper is to propose a generic modelling framework for describing the exchange of information between health institutions in the context of patient's care, concerning a given chronic pathology. The purpose is to facilitate building of flow models starting from the proposed modelling framework, those models will be used to support quantitative evaluation through discrete event simulation, useful to evaluate the impact of communication between health institutions on patient care pathway. This work is a part of a research project entitled e-SIS (“Assessment in Health Information Systems"), project funded by the French health ministry (DGOS) as part of its research program called PREPS ("Research Program on Performance of Healthcare Systems").
\end{abstract}

Keywords: patient care pathway, hospital, City health facilities, information systems, interactions, generic modelling framework.

\section{Introduction}

Health systems around the world are in crisis because of the increase of care expenditures whereas resources become limited [1]. The French health system is constrained in the same way and faces since many years an increase mainly related to care spending which can be explained, in part, by the increase in care demand due to the population aging and also the increase of the number of people with chronic diseases. On the other hand, the increase in health spending is explained by the many frontiers that separate the French health system and generate costs: the barriers, now considered as non-quality, could explain up to $15 \%$ unjustified costs [1], the main partitioning being between hospitals and private practitioners.

To tackle this problem, it is important to reorganize the health system around the patient's care pathway [2]. Given that the hospital represents itself a care pathway, organized and coordinated by the hospital information system, it seems judicious to export that model outside the hospital walls, by implementing e-health platforms and 
the interfaces between such platforms and all the information systems of health institutions within a territory. The goal consists in having a health information system which is computerized and integrated, enabling the continuity of care and the traceability in patients' pathways. Such approach is motivated by the fact that organizational problems related to patient care (delays between health-care stays, ruptures in patient pathway...) are primarily related to a lack of communication between health institutions, which lead to a lack of coordination between the different health actors involved in the patient's care [3].

This work is a part of a research project entitled e-SIS (French acronym for "Assessment in Health Information Systems"), project funded by the French health ministry (DGOS) as part of its research program called PREPS (French acronym for "Research program on performance of health-care systems"). The project aims to assess the impact of information systems on creating value in health facilities.

As regards the quantitative evaluation of HIS, there is no study that takes into account, at the same time, human, organizational and technological aspects of an IS and their impacts on values' creation within health institutions [4]. Whereas for the modelling of HIS, some authors have proposed flow models which were described using graphical formalisms such as UML [5] and $3 \mathrm{LGM}^{2}$ [6], except that these models describe only the flow of electronic information among computer systems within an IS, neglecting thus the human and organizational aspects. Other authors, for their part, have proposed models to exclusively describe patients' flows through their care pathway, using formalisms such as BPMN, SADT or also Petri Nets [7] [8].Therefore, there has not been, to our knowledge, a modelling framework that jointly describe the flows of patients and information within a one and only model representing a health institution or territory.

Thus, before achieving such evaluation, a modelling work of cancer care system should be performed upstream. For that reason, we decided to implement a modelling framework based on the process approach. Then starting from the proposed modelling framework we belt a flow model which will support the quantitative analysis (through discrete event simulation), the ultimate objective being to evaluate the impact of information exchanges between a hospital and a city health facilities on patient cancer pathway.

This paper is organized as follows: position of the problem is presented in Section 2. A generic modelling framework for describing the management system of information exchanged between health institutions within the context of patient pathway is described in Section 3. Finally, conclusions and perspectives are given in Section 4.

\section{Position of the Problem}

Anyone who is suffering from a chronic disease, such as cancer, follows a double care pathway: (i) In-hospital, within a hospital centre or a specialized centre for cancer care, and (ii) out-hospital, within city health facilities (General Practitioners (GP) offices, biological analysis laboratories, rehabilitation care facilities, hospital at home structures...). The role of hospitals is to provide a highly specialized diagnosis 
and treatment, which will be supported by an out- hospital care, provided by city health facilities.

On the other hand, patient's care at a health facility (hospital or city facility) requires external medical information provided by other health facilities; patient's care at that facility will also create, by the same occasion, medical information that will be required as a result of patient care in other health facilities. It is noteworthy that the exchange of information between institutions is done through one or more communication interfaces (e.g. postal mail, secure electronic messaging, shared patient record, etc.), each interface being characterized by a cost, related to resources used to transmit information, as well as an information delivery delay.

Given that the actual literature does not provide models or tools that allow assessing quantitatively the impact of information systems on patient pathway, the aim of this work is to propose a generic modelling framework for describing both patient pathway and the exchange of information between health institutions in the context of patient's care, concerning a given chronic pathology. Such framework should be compact and simple enough to be used by any stakeholder to build the specific model of a patient pathway including all HIS available in the environment. The resulting model can be used to support risk analysis and discrete event simulation, in order to assess the impact of health institutions' communication on the patient care pathway.

\section{A Generic Modelling Framework for Describing the Management System of Information Exchanged between Health Institutions within the Context of Patient Pathway}

In the perspective of assessing the impact of interactions between the hospital and the city health facilities on patient's cancer pathway, we have decided to implement a generic modelling framework for describing the management system of medical information which are exchanged between health institutions within the context of healthcare for patients suffering from a chronic disease. This modelling framework uses the process approach as a modelling method, as well as the BPMN (Business Process Model and Notation) as a graphical formalism with, however, some modifications made on that formalism. Furthermore, any model built starting from the proposed modelling framework will be represented according to two views : (i) a « Patient pathway » view and (ii) a «Shared health information system » view. The aim of such modelling structure is to increase the readability of the model and therefore the intelligibility of the described system.

(i) The « Patient pathway » view: described on one hierarchical level, it makes explicit all healthcare processes that can compose a patient pathway regarding a given disease (e.g. medical consultation, biological analysis examination, surgery, etc.) as well as the articulating of these processes, i.e. the various possibilities of process sequences. In order to illustrate our point, we will give the example of the patient's cancer pathway (see Fig. 1). The figure below describes the cancer patient's pathway 
through the processes that compose it: the red area constitutes the in- hospital care, while the green area will constitute the out-hospital care (within city health facilities).

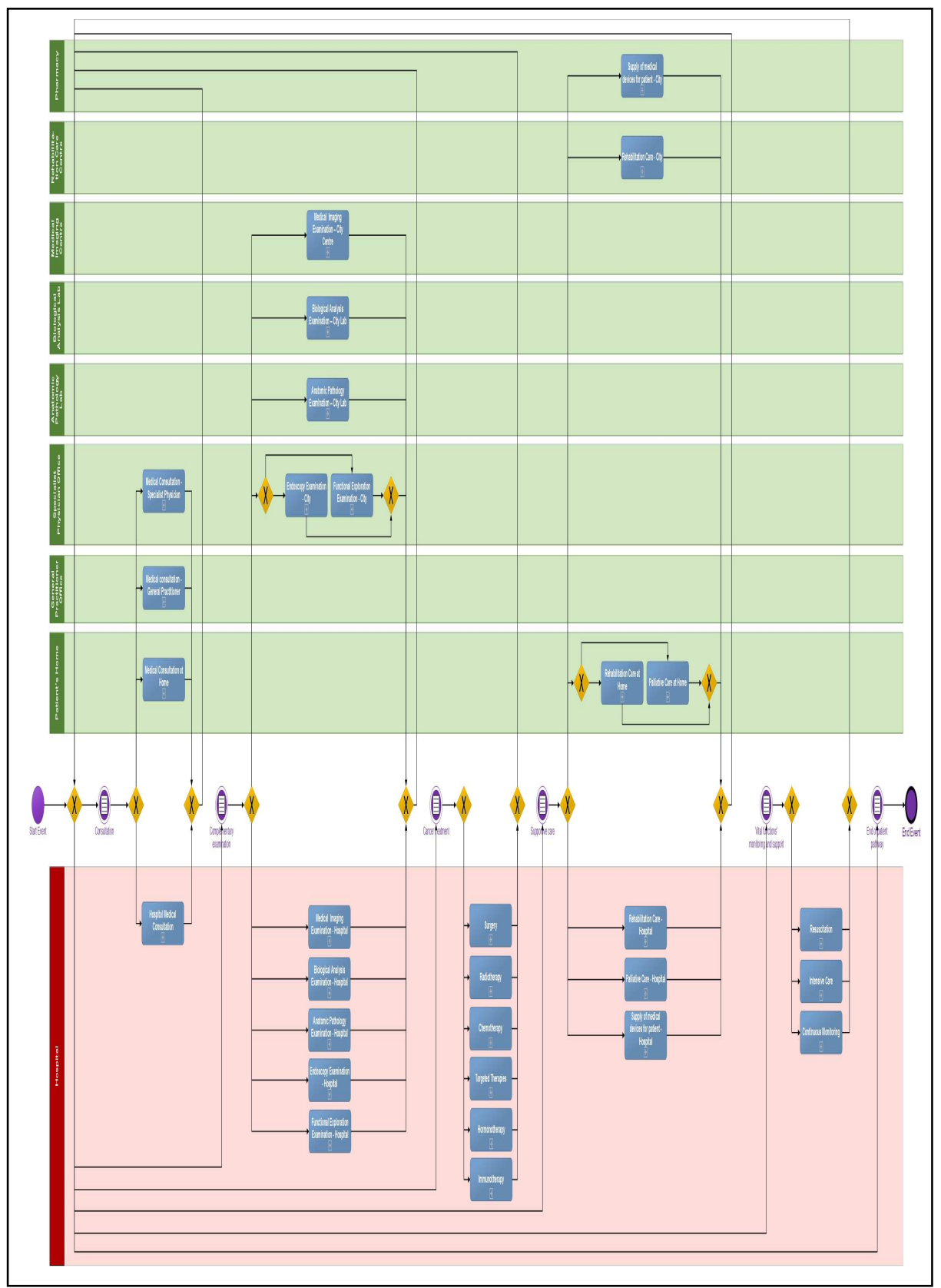

Fig. 1. The cancer patient's pathway 
(ii) The « Shared health information system » view: described for its part on three hierarchical levels:

Level 3: representing the highest level of abstraction, it allows describing for each process, implemented within a given health facility, its potential interactions (or information exchanges) with all processes implemented in other health facilities, knowing that the transmission of information can be done directly between two processes through a direct communication interface (e.g. postal mail, electronic messaging, fax, etc.), or indirectly by feeding an electronic patient record shared between health facilities within the health territory. Let's take as example the "hospital's medical consultation" process which interacts with two other processes occurring outside the hospital (see Fig. 2).

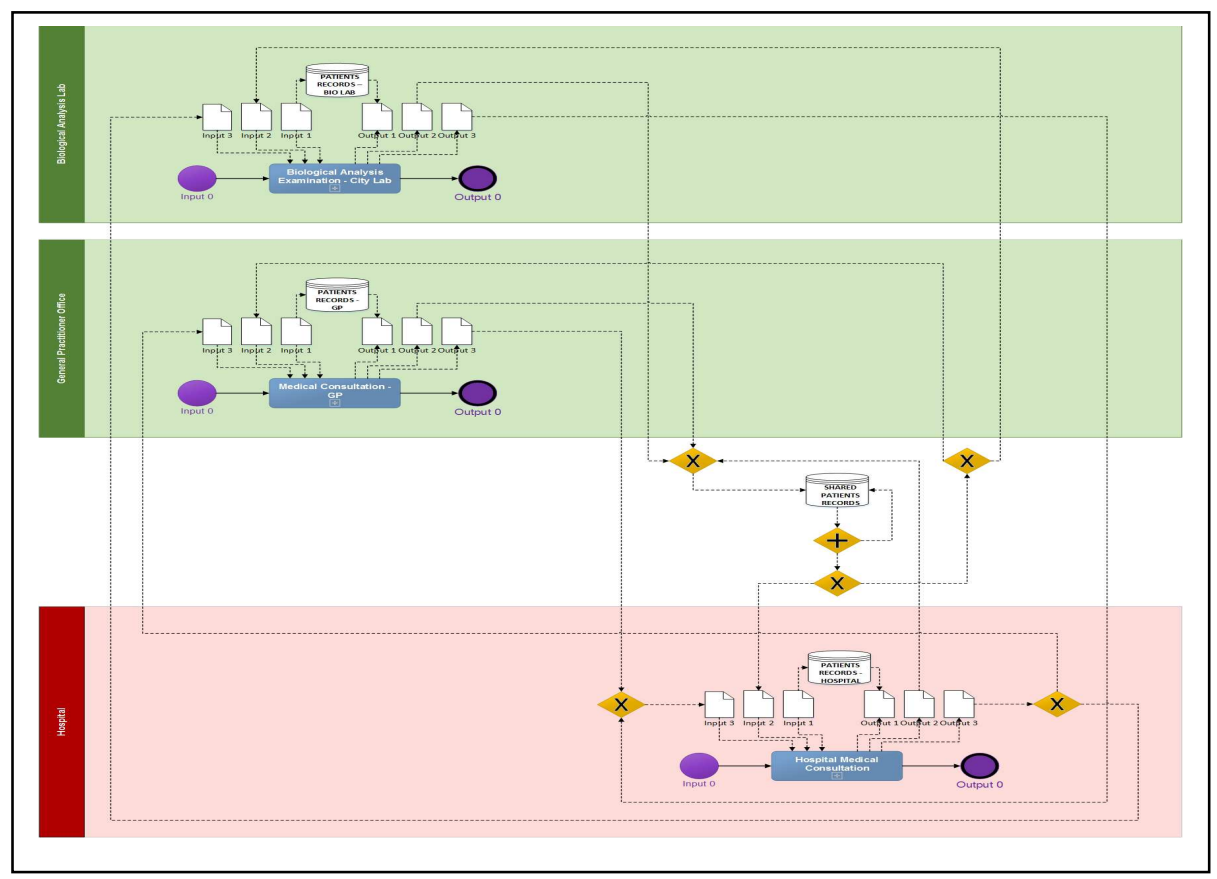

Fig. 2. Information exchanges between healthcare processes

We can see that each process has four inputs and four outputs. An input (I/P0) for the "Patient" entity, and three inputs for entities of "Information" type: I / P1 for the information received through a direct communication interface, I/P2 for the information that are available on an electronic patient record shared within the health territory, and I/P3 for the information that are already available on the patient record of the health facility which implements the described process. Idem for the outputs, there is one output $(\mathrm{O} / \mathrm{P} 0)$ for the entity "Patient" and three outputs for entities of "Information" type : O/P1 for information that has been exploited and which need to be (re)integrated into the patient record of the health facility, O/P2 for the information that will feed the electronic patient record shared within the health territory, and 
finally $\mathrm{O} / \mathrm{P} 3$ for the information transmitted to another process via a direct communication interface (postal mail, fax...).

Level 2: describes each process from the view of the shared health information system, i.e. from the view of the management of medical information received or sent by the described process. The management of these information is performed through the concatenation of a number of dedicated activities which are (at most) in number of seven: (1) Receive an information, (2) Integrate an external information into the patient record, (3) Retrieve the patient record, (4) archive the patient record, (5) Consult an external information, (6) Produce an information and (7) Communicate an information (see Fig. 4). We can distinguish in that figure the four inputs and the four outputs of the process. We can also distinguish two types of transitions: the ones with an arrow in solid line correspond to patient flows, while dotted arrows represent information flows. Furthermore, we can see that the execution of some activities may require synchronization between the "patient" entity and an "information" entity such as for the activity "Consult an information".

Moreover, it is important to emphasise the generic nature of that level which allows describing any healthcare process from the point of view of the shared health information system, regardless the degree of development of the facility's information system (a paper or an electronic patient record, a non integrated or a highly integrated computer system, etc.).

Level 1: finally, this level allows describing the implementing procedures of each activity composing a given process: each activity has at least one implementing procedure, each procedure is characterized by a delay and a cost related to the mobilization of human, hardware, software and network resources which are necessary for its achievement. Example: The implementing procedures of the activity "Communicate an information" for the process "Medical consultation" within a hospital having an electronic patient record (see Fig. 3).

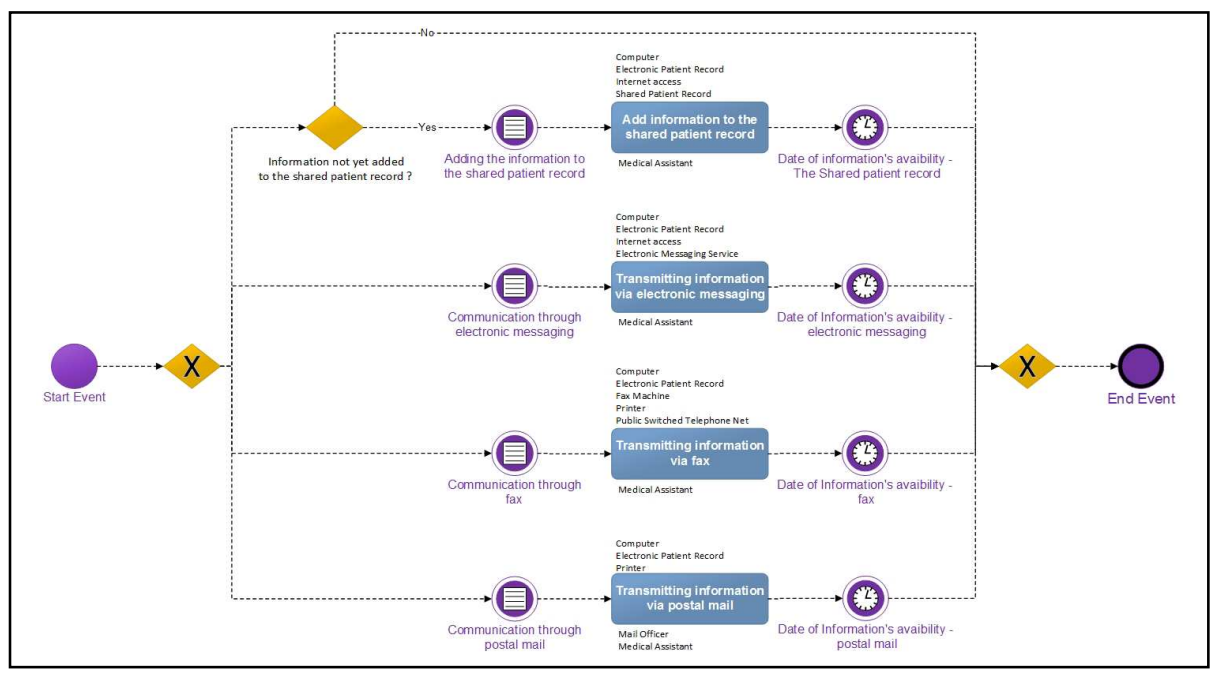

Fig. 3. The implementing procedures of the activity "Communicate an information" within the context of a medical consultation" at a hospital 
Modelling interactions between health institutions in the context of patient pathway 7

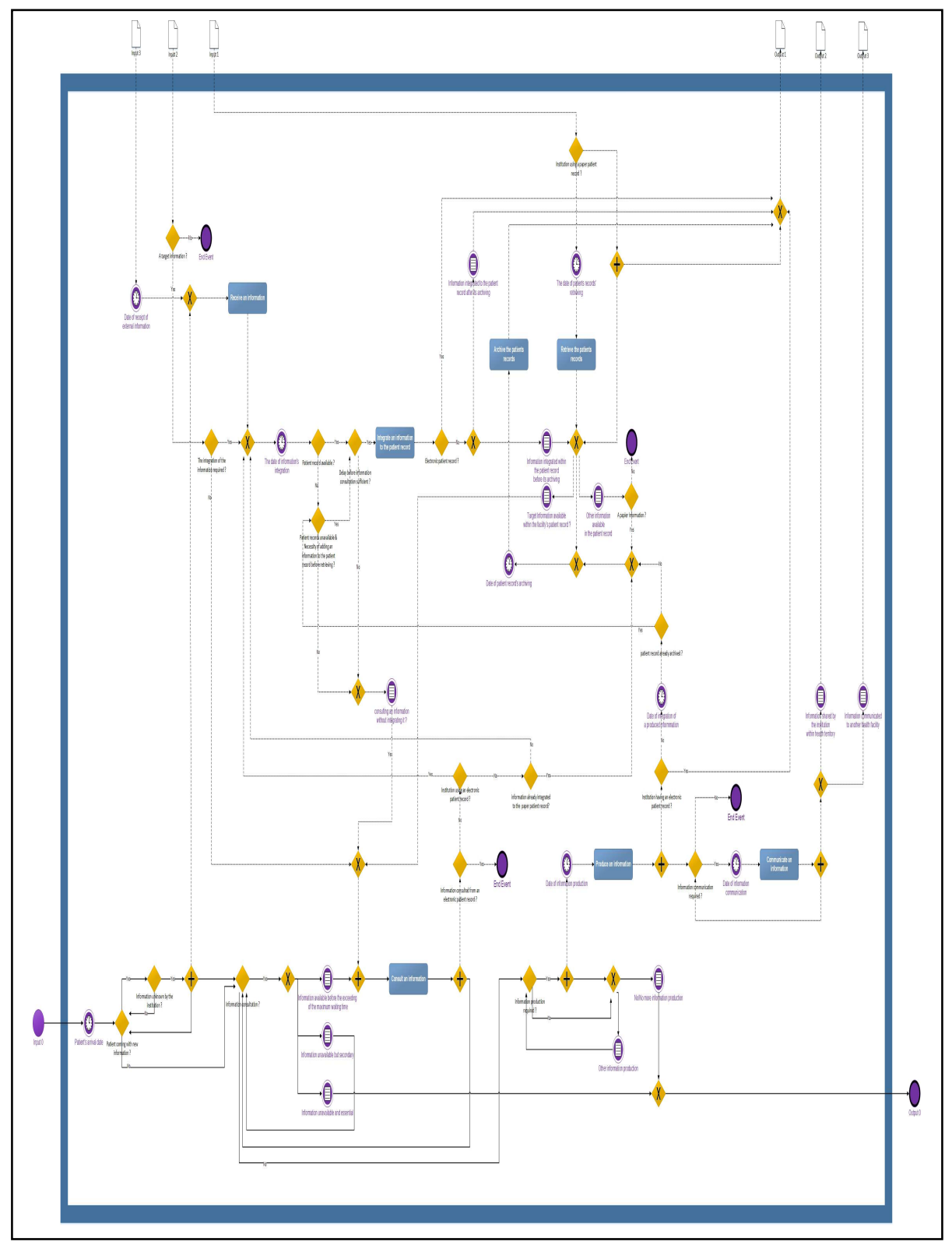

Fig.4. The generic description of a healthcare process from the view of the shared health information system 


\section{Conclusion}

In this paper we proposed a new framework based on the process approach for patient pathway and information modelling. We first defined the context of the study in the e-SIS project. Then we presented the basics of the modelling framework which allows describing the management system of information exchanged between health institutions within the context of patient pathway. The resulting models will be used to support simulation for performance evaluation.

In future work we are currently working on the development of a rigorous methodology to propose a performance evaluation of the health information system on the regional level. Such quantitative evaluation will be performed taking into account (i) patient quality of care, (ii) working conditions of health-care professionals, and (iii) economic evaluation of health structures.

Acknowledgments. The authors would like to thanks practitioners from the Centre Léon Bérard: L. Perrier, P. Biron, T. Durand; CH Sens: S. Aloui; Centre Jean Perrin: A. Doly.

\section{References}

1. Bourret, C. Partager l'information pour dépasser les frontières institutionnelles et professionnelles ou le défi des réseaux de santé dans le système de santé français. In 35th Annual Conference Information Sharing in a Fragmented Word (2007).

2. ARS Centre, (The Regional Agency for Health - Centre region, France). Stratégie nationale de santé et enjeux régionaux d'une médecine de parcours; Comment améliorer le service rendu au patient. Première journée des rencontres de la santé, (2013).

3. Caillavet-Bachellez, V. «Le parcours de soins du patient : un dispositif fédérateur pour les Communautés Hospitalières de Territoire (CHT) », Ecole des Hautes Etudes en Santé Publique (EHESP), (2010).

4. Yusof, M. M., Papazafeiropoulou, A., Paul, R. J., \& Stergioulas, L. K.. Investigating evaluation frameworks for health information systems. International journal of medical informatics, 77(6), 377-385. (2008).

5. Spyrou, S., Bamidis, P., Pappas, K., \& Maglaveras, N. Extending UML activity diagrams for workflow modelling with clinical documents in regional health information systems. In Connecting Medical Informatics and Bioinformatics: Proceedings of the 19th Medical Informatics Europe Conference (MIE2005). Geneva, Switzerland (pp. 1160-1165). (2005).

6. Winter, A., Brigl, B., \& Wendt, T. Modeling hospital information systems (part 1): the revised three-layer graph-based meta model 3LGM2.Methods of Information in MedicineMethodik der Information in der Medizin,42(5), 544-551. (2003).

7. Augusto, V., \& Xie, X. Modélisation et analyse de flux par la simulation en milieu hospitalier : état de l'art. Conférence Gestion et Ingénierie des SystEmes Hospitaliers (GISEH), Luxembourg (2006).

8. Ozcan, Y. A., Tànfani, E., \& Testi, A.. A simulation-based modeling framework to deal with clinical pathways. In Proceedings of the Winter Simulation Conference (pp. 11901201). Winter Simulation Conference (2011). 